\title{
Behavioral components of shock-induced aggression in ground squirrels (Citellus tridecemlineatus)*
}

\author{
JIM L. TURNER †. ROBERT BOICE, and PATRICK C. POWERS $\dagger \dagger$ \\ Liniversity of Missouri, Columbia, Missouri 65201
}

\begin{abstract}
The fighting behavior of paired ground squirrels was observed in a footshock chamber, with shock offset contingent on pair members displaying an unambiguous dominant-subordinate relationship. Status relations stabilized over days, resulting in a decrease in the intensity and duration of encounters and an increase in the frequency of threat displays. Various agonistic components are described and their functions and effects discussed in terms of naturally occurring aggression in this species.
\end{abstract}

Field studies of agonistic interaction in ground squirrels (Citellus) typically report that intense conflict is rare, with aggressive encounters seldom resulting in serious injury (Balph \& Stokes, 1963: Wirtz, 1967). These observations, however, are limited to a restricted sample of above-ground encounters and there is some indication that more intense fighting may occur in the confines of burrows (Rongstad, 1965). It is also likely that the majority of field encounters involve individuals who have had prior contacts and who may have already established relatively stable status relations. Since initial contact, or a series of early encounters, is usually of critical importance in deciding dominance (Ginsberg \& Allee, 1942; Clark \& Schein, 1966; Collias, 1950), intense activities may be confined to this formative stage, with subsequent interaction characterized by social posturing or flight. The problem, of course, is that field study of rodents provides limited opportunity for identifying individuals or for accurately assessing the frequency and quality of prior contacts. These considerations point out the need for developing laboratory methods that permit more controlled study of aggressive forms and processes in wild rodents.

The elicited aggression paradigm, where paired animals are placed in a small chamber and footshocked, ensures fighting and has recently been employed for postural analysis of dominant-subordinate interactions in laboratory rats (Reynierse, 1971). If this technique can be usefully extended to wild ground squirrels, it may supplement field observation by permitting more detailed study of the functions and effects of various agonistic components under highly controllable conditions.

\footnotetext{
*Filming and preparation of figures was financed by a predoctoral grant from the National Institute of Health (MH-48698) to Jim L. Turner.

† Present address: Sociobehavioral Research, Neuropsychiatric Institute, UCLA, 760 Westwood Plaza, Los Angeles, California 90024.

††The authors thank Professor X. J. Musacchia, Space Sciences Research Center, University of Missouri, for providing the ground squirrels. Dr. Musacchia was coauthor of an earlier version of this paper presented at the 1970 AAAS meetings, Chicago.
}

Although the use of electric shock and space restriction to induce conflict is notably artificial, there is some indication that basic behavioral processes evoked under these conditions are similar to those occurring in more natural settings. Hutchinson et al (1965), for example, note that shock-induced aggression resembles naturally occurring conflict with respect to hormonal and experiential variation, while Logan and Boice (1969) report that species of rodents which differ in frequency and intensity of social contacts in the wild maintain their characteristic patterns of agonistic behavior when paired and shocked in an avoidance learning context. Further, the development of dominant-subordinate relations during shock-elicited conflict has been consistently noted by various investigators (e.g., Reynierse, 1971; Baenninger \& Grossman, 1969; Logan \& Boice, 1969).

On the other hand, there has been a general concern that elicited aggression procedures may have limited applicability for studying the sociobehavioral aspects of intraspecific aggression. A major issue in this regard is the extent to which the experimental context disrupts social mechanisms while evoking reflexive stress reactions that are more "defensive" than "aggressive" (Uyeno \& White, 1967; King, 1966; Scott, 1966). Reynierse (1971), for instance, has suggested that elicited aggression findings may be more appropriately related to a predator-prey context than to intraspecific conflict. Support for this viewpoint is based primarily on the observation that shocked laboratory rats emit an attentuated and ambivalent sample of postures and activities.

Another suggested limitation of the elicited aggression technique is that it can only be applied to relatively unaggressive strains of animals (Ulrich, 1966; Scott, 1966). Wild and/or nondocile rodents have, thus, generally been excluded from such research, presumably on the basis that fatalities preclude extended study.

These two alleged limitations of the elicited aggression method combine to produce a circular and potentially misleading argument. To begin with, it may be that laboratory rats have an impoverished agonistic repertoire compared to undomesticated forms (King, 1966; 
Barnett, 1958). Thus. their behavior under elicited aggression conditions is consistent with their behavior in less contrived situations and could be interpreted as a species-specific type and level of defensive reactivity (e.g., Bolles, 1970), a reflection of the choice of experimental animal rather than experimental procedure. So long as comparative study is constrained by the docility assumption, however, this alternative explanation can never be adequately tested.

Further, most elicited aggression research has focused on the study of learning processes rather than on the description and analysis of agonistic behavior. Exclusion of undomesticated rodents may thus be due, in part, to a theoretical rationale that favors a tractable species with limited genetic variation. In any case, a search of the literature revealed no previously reported study of shock-induced aggression in ground squirrels.

It is also likely that certain features of the footshock method, as standardized by Ulrich and his colleagues (Ulrich, 1966; Hutchinson et al, 1965), can be modified to enhance the salience of intraspecific responses. Most of the work with laboratory rats has employed an unavoidable, inescapable shock contingency. As Reynierse (1971) has pointed out, such conditions are highly effective in producing generalized stress reactions and have the cumulative effect of inducing fear-motivated passivity. Thus, with additional noncontingent shock trials, intraspecific activities may become increasingly uncharacteristic as Ss develop a type of "conditioned helplessness" (Seligman \& Maier, 1967).

In an effort to avoid this pattern of events, the present study employed an "escape training" procedure in which termination of shock was contingent on postural resolution of social dominance. It was anticipated that adoption of this instrumental component would: (1) enhance and maintain the salience of exteroceptive stimuli, with additional trials increasing rather than decreasing the likelihood of Ss assuming socially functional displays, and (2) lead to a fairly rapid decrease in biting, with less intense activities being sufficient to resolve dominance and terminate shock. The intent here was to devise an experimental situation that reinforced (i.e., shock offset) those inhibitory mechanisms and social cues presumably operative under natural conditions. If such an analysis is viable, this type of escape contingency should minimize physical injury while evoking a reasonable approximation of the forms and processes of intraspecific conflict.

Given the above considerations, a general objective of the present study was to examine the suitability of using footshock procedures for studying the agonistic components of dominant-subordinate interaction in wild ground squirrels. Specific predictions were that: (a) each pair of Ss would develop a relatively stable dominant-subordinate relationship. (b) with postural displays supplanting intense behaviors as the characteristic mode of status resolution. (c) resulting in a concomitant decrease in the intensity and duration of encounters.

\section{METHOD}

Ten adult ground squirrels (Citellus tridecemlineatus), five male and five female, were wild trapped and caged individually in molded plastic cages with wood shavings. Ss had free access to food and water and were maintained for 9 months prior to testing to effect some habituation to captivity (Denniston, 1959). Preexperimental handling of Ss was confined to weekly cage cleaning, with no apparent increase in docility resulting from these brief contacts. None of the Ss hibernated during their winter of captivity. Testing began in late spring at a time when all males had swollen scrotal testes. An identifying number was stenciled on the back and stomach of each animal as testing began.

The experimental chamber was $29 \times 14 \times 50 \mathrm{~cm}$ high. An opaque guillotine door was lowered between trials, dividing the chamber into two equally small compartments. The chamber was fronted by a glass wall, permitting unobstructed observation of Ss. Electric shock at $200 \mu \mathrm{A}$ and $40 \mathrm{~V}$ dc was delivered via stainless steel grids spaced $1.5 \mathrm{~cm}$ center to center in series with NE 2 neon bulbs, so that Ss were shocked when in contact with any two grids.

Ss were transferred by gloved hand from their home cages to the experimental chamber and returned to their individual home cages after each pairing. A daily session consisted of pairing each $\mathrm{S}$ with every other $\mathrm{S}$ for one trial each. Daily sessions typically required $150 \mathrm{~min}$ to complete and were conducted for 10 consecutive days. The sequence of pairings within a daily session was randomized. with the added stipulation that no $S$ be involved in successive encounters.

Trials were initiated with a foot pedal which raised the door separating the two animals and started a clock. Five seconds later the timer activated shock that continued until the $E$ released the foot pedal.

Encounters (and shock) were terminated when one animal displayed submissive posturing in apparent response to the dominant role behavior of the other pair member. In its extreme form, criterion submission involved the subordinate animal lying immobile on its side or back with head averted and eyes closed. Although some of these components might not appear in a given encounter, all criterion judgments required that the subordinate animal be motionless and avoiding eye contact. The behavior of the dominant pair member was also critical in judgments of criterion submission. Thus, the nonsubmissive animal had to be in close proximity and displaying the concomitant dominant attitudes of visual and postural orientation toward the subordinate.

The same two observers (i.e.. the first and third authors) were present throughout the study. One $\mathrm{E}$ operated the shock chamber and called a running account of the behaviors of both animals. The other coded the frequency and sequencing of preselected behavioral categories on a prepared record form. Judgments regarding criterion submission required immediate interobserver agreement before shock was terminated. Trials with $30 \mathrm{sec}$ of shock and no criterion submissive response were terminated and judged a tie. Following each trial the record form was reviewed until both observers concurred on the accuracy of all coded events. Supplementary notes were also added to the record at this time. Facility in this procedure. as well as selection of behavioral categories and development of the coding system. was achieved during 2 weeks of pilot study with ground squirrel Ss other than those included in the present report.

Brief operational definitions of those behavioral sategoriss relevant to the present report are as follows:

Aroiding Shock. A stereotyped response direstly elicited by shock itself and not antributable to any social stimulus. 
Behaviorally this consists of a circular prancing movement with back arched and facial orientation to the grid floor.

Made Initial Attack. Identifies those instances in which initial physical contact in an encounter is clearly attributable to the approach movements of a particular individual. i.e., the other animal either remained in a stationary position or moved to avoid an approaching pair member. Apparent accidental contacts, such as might occur when one or both animals are avoiding shock, are not counted as attacks.

Mutual Attack. Simultaneous approach movements resulting in physical contact. As in "initial attack," this category refers only to the first instance of physical contact within an encounter and involves the judgment that movements of both animals are head-on and oriented toward establishing such contact.

Aloids Attack of Other. A S is judged to be avoiding attack when its movements and facial orientation are directed away from an approaching pair member. Continuation of movement is the critical feature distinguishing attack avoidance from criterion submission. That is, head/eye aversion coupled with mobility is categorized as avoiding attack, while head/eye aversion coupled with immobility is termed "criterion submission."

Displays Threat Posture. This category subsumes all those instances in which an animal's initial approach movements stop short of physical contact while maintaining eye fixation and a rigid head-on postural orientation in close proximity to the other pair member. A mutual threat category was used to identify those occasions during which pair members exhibited these behaviors simultaneously.

Sparring. Both animals assume an upright stance with forelegs extended in front of the chest. Active sparring consists of rapid extension and retraction of the forelegs while maintaining close proximity and mutual visual orientation.

Wrestling. Individuals are clasping and/or biting each other and are rolling over and over on the floor.

Down on Side or Back. Refers to those instances in which one or both pair members either lose their footing or are knocked down and remain temporarily immobile without showing a criterion submissive response.

Vocalization. Two distinct calls are to be discriminated. The first is a sustained low-pitched whimper, while the second is a high-pitched chirp delivered in short bursts.

Biting. The frequency and location of apparent biting will be noted during the course of an encounter. Postencounter examination of the animal is then used to detect wounds. If no wound was found in the suspected area, biting is not coded.

Approximately one-third of the experimental encounters were recorded on Kodak TRI-S high-speed $16-\mathrm{mm}$ film. The camera was mounted on a tripod and operated by remote switch. Three $S$ pairs (one male-male, one female-female, one male-female) were arbitrarily chosen to be filmed throughout the study, with other pairings selected randomly. The result was a film record of 12 complete encounters per day. This record served as a critical check on the general accuracy of coded observations and also permitted a more detailed postural analysis of encounters.

Due to severe injuries, including loss of top front teeth, it was necessary to remove one female $S$ from the study on the third day of testing. Data obtained on this $S$ are excluded from the present analysis.

\section{RESULTS}

A status hierarchy based on the rank order of win/loss (dominant/submissive) ratios (Baenninger, 1970) was computed for each day of testing. By Day 7, all positions in the hierarchy had stabilized and approached transitivity, with individuals nearly always dominating animals below them in overall rank and submitting to those above them. The top-ranking $S$ and the two lowest ranking squirrels remained in their respective positions
Table 1

Relationship Between Rank on Day 10, Sex, Body Weight, and Overall Outcomes

\begin{tabular}{|c|c|c|c|c|c|c|}
\hline \multirow{2}{*}{$\begin{array}{c}\text { Rank } \\
\text { (Day } \\
10 \text { ) }\end{array}$} & \multirow{2}{*}{ Sex } & \multirow{2}{*}{$\begin{array}{l}\text { Weight } \\
\text { (grams) }\end{array}$} & \multicolumn{4}{|c|}{ Outcomes Over All Encounters } \\
\hline & & & Won & Lost & Tied & Total \\
\hline 11 & Male & 215.0 & 78 & 1 & 1 & 80 \\
\hline 2 & Male & 197.3 & 55 & 18 & 7 & 80 \\
\hline 3 & Male & 234.0 & 50 & 25 & 5 & 80 \\
\hline 41 & Male & 311.0 & 45 & 32 & 3 & 80 \\
\hline $5 \mathrm{I}$ & Female & 270.0 & 36 & 41 & 3 & 80 \\
\hline 6 & Female & 162.0 & 30 & 44 & 6 & 80 \\
\hline 7 & Female & 215.1 & 30 & 49 & 1 & 80 \\
\hline 8 & Male & 168.7 & 15 & 58 & 7 & 80 \\
\hline 91 & Female & 274.3 & 3 & 74 & 3 & 80 \\
\hline
\end{tabular}

throughout all test sessions. Shifts in daily rank were, thus, confined to middle-rank animals during the first 6 days of testing. The major consistency in these daily status shifts was the tendency for middle-ranking males to move upward in rank, while middle-ranking females moved downward.

One further concern regarding status stability was the effect of prior outcomes within a daily session on subsequent encounters in the same session. Suppose, for example, that the seventh-ranking animal was initially paired with two lower ranking squirrels and won both encounters. Meanwhile, the fifth-ranking $S$ had met two animals of higher status and had been defeated twice. Would the low-ranking winner now defeat the higher ranking loser? Seven instances were observed in which Ss differing by at least two increments in overall rank met under this type of circumstance. In only one instance did the lower ranking animal win the encounter. Moreover, there was no indication that these bouts differed significantly in duration or intensity from other encounters involving the same individuals.

Table 1 lists final rank, total outcomes over all test sessions, sex, and body weight of the Ss. As indicated in the table, females were generally subordinate to males, although body weight did not correlate significantly with final rank $($ Rho $=0.08)$.

Encounters were generally brief, with criterion submission occurring within 10-15 sec of shock onset. Male-male pairings were significantly longer than female-female pairings $(t=3.56, p<.001)$, with male-female encounters of intermediate duration. Mean encounter times decreased gradually over days from a high of $19.05 \mathrm{sec}$ on Day 2 to a low of $9.59 \mathrm{sec}$ on Day 10. In only three instances did criterion submission occur within the 5-sec preshock interval. All such cases involved the alpha male during the latter 2 days of testing.

There was a major discrepancy between mean encounter time on Day 1 and subsequent early sessions. This was due primarily to an arbitrary decision to terminate those trials involving a particular type of biting behavior. Many of the encounters on Day 1, for example, involved one animal locking its teeth on the 
Table 2

Incidence of Selected Behaviors in Paired Ground Squirrels

\begin{tabular}{|c|c|c|c|c|c|c|c|c|c|c|c|c|}
\hline $\begin{array}{l}\text { Daily } \\
\text { Session } \\
\text { Number }\end{array}$ & $\begin{array}{c}\text { Status } \\
\text { of Pair } \\
\text { Member }\end{array}$ & $\begin{array}{l}\text { Avoid- } \\
\text { ing } \\
\text { Shock }\end{array}$ & $\begin{array}{c}\text { Made } \\
\text { Initial } \\
\text { Attack }\end{array}$ & $\begin{array}{l}\text { Avoids } \\
\text { Attack } \\
\text { of Other }\end{array}$ & $\begin{array}{c}\text { Displays } \\
\text { Threat } \\
\text { Posture }\end{array}$ & $\begin{array}{l}\text { Down } \\
\text { on Side } \\
\text { or Back }\end{array}$ & $\begin{array}{l}\text { Biting } \\
\text { Other }\end{array}$ & $\begin{array}{l}\text { Vocali- } \\
\text { zation }\end{array}$ & $\begin{array}{l}\text { Mutual } \\
\text { Attack }\end{array}$ & $\begin{array}{c}\text { Mutual } \\
\text { Threat } \\
\text { Postures }\end{array}$ & $\begin{array}{l}\text { Spar- } \\
\text { ring }\end{array}$ & $\begin{array}{l}\text { Wrestl- } \\
\text { ing }\end{array}$ \\
\hline 1 & $\begin{array}{l}\text { Dominant } \\
\text { Subordinate }\end{array}$ & $\begin{array}{r}7 \\
10\end{array}$ & $\begin{array}{r}27 \\
4\end{array}$ & $\begin{array}{r}2 \\
14\end{array}$ & $\begin{array}{l}1 \\
0\end{array}$ & $\begin{array}{r}5 \\
24\end{array}$ & $\begin{array}{l}22 \\
12\end{array}$ & $\begin{array}{l}17 \\
22\end{array}$ & 5 & 3 & 18 & 21 \\
\hline 2 & $\begin{array}{l}\text { Dominant } \\
\text { Subordinate }\end{array}$ & $\begin{array}{l}3 \\
5\end{array}$ & $\begin{array}{l}21 \\
11\end{array}$ & $\begin{array}{l}1 \\
5\end{array}$ & $\begin{array}{l}0 \\
1\end{array}$ & $\begin{array}{l}22 \\
27\end{array}$ & $\begin{array}{l}24 \\
19\end{array}$ & $\begin{array}{l}16 \\
21\end{array}$ & 4 & 2 & 31 & 31 \\
\hline 3 & $\begin{array}{l}\text { Dominant } \\
\text { Subordinate }\end{array}$ & $\begin{array}{l}2 \\
4\end{array}$ & $\begin{array}{l}14 \\
13\end{array}$ & $\begin{array}{l}0 \\
3\end{array}$ & $\begin{array}{l}3 \\
2\end{array}$ & $\begin{array}{l}17 \\
32\end{array}$ & $\begin{array}{l}24 \\
17\end{array}$ & $\begin{array}{l}23 \\
24\end{array}$ & 9 & 4 & 30 & 31 \\
\hline 4 & $\begin{array}{l}\text { Dominant } \\
\text { Subordinate }\end{array}$ & $\begin{array}{l}4 \\
3\end{array}$ & $\begin{array}{l}17 \\
13\end{array}$ & $\begin{array}{l}0 \\
5\end{array}$ & $\begin{array}{l}6 \\
2\end{array}$ & $\begin{array}{l}16 \\
23\end{array}$ & $\begin{array}{r}14 \\
7\end{array}$ & $\begin{array}{l}22 \\
23\end{array}$ & 6 & 1 & 32 & 24 \\
\hline 5 & $\begin{array}{l}\text { Dominant } \\
\text { Subordinate }\end{array}$ & $\begin{array}{l}5 \\
5\end{array}$ & $\begin{array}{l}15 \\
14\end{array}$ & $\begin{array}{l}0 \\
3\end{array}$ & $\begin{array}{l}8 \\
2\end{array}$ & $\begin{array}{r}4 \\
21\end{array}$ & $\begin{array}{l}8 \\
2\end{array}$ & $\begin{array}{l}21 \\
25\end{array}$ & 7 & 3 & 33 & 14 \\
\hline 6 & $\begin{array}{l}\text { Dominant } \\
\text { Subordinate }\end{array}$ & $\begin{array}{l}10 \\
10\end{array}$ & $\begin{array}{r}16 \\
9\end{array}$ & $\begin{array}{l}0 \\
5\end{array}$ & $\begin{array}{r}19 \\
2\end{array}$ & $\begin{array}{r}1 \\
16\end{array}$ & $\begin{array}{l}3 \\
0\end{array}$ & $\begin{array}{l}30 \\
28\end{array}$ & 11 & 6 & 29 & 5 \\
\hline 7 & $\begin{array}{l}\text { Dominant } \\
\text { Subordinate }\end{array}$ & $\begin{array}{l}4 \\
6\end{array}$ & $\begin{array}{l}18 \\
11\end{array}$ & $\begin{array}{l}0 \\
4\end{array}$ & $\begin{array}{r}15 \\
6\end{array}$ & $\begin{array}{r}1 \\
23\end{array}$ & $\begin{array}{l}6 \\
0\end{array}$ & $\begin{array}{l}30 \\
29\end{array}$ & 7 & 2 & 32 & 8 \\
\hline 8 & $\begin{array}{l}\text { Dominant } \\
\text { Subordinate }\end{array}$ & $\begin{array}{l}3 \\
2\end{array}$ & $\begin{array}{l}17 \\
12\end{array}$ & $\begin{array}{l}0 \\
5\end{array}$ & $\begin{array}{r}12 \\
4\end{array}$ & $\begin{array}{r}2 \\
22\end{array}$ & $\begin{array}{l}4 \\
0\end{array}$ & $\begin{array}{l}30 \\
28\end{array}$ & 7 & 3 & 32 & 11 \\
\hline 9 & $\begin{array}{l}\text { Dominant } \\
\text { Subordinate }\end{array}$ & $\begin{array}{l}5 \\
5\end{array}$ & $\begin{array}{r}18 \\
8\end{array}$ & $\begin{array}{l}0 \\
4\end{array}$ & $\begin{array}{r}18 \\
4\end{array}$ & $\begin{array}{r}0 \\
16\end{array}$ & $\begin{array}{l}4 \\
0\end{array}$ & $\begin{array}{l}34 \\
31\end{array}$ & 10 & 3 & 31 & 4 \\
\hline 10 & $\begin{array}{l}\text { Dominant } \\
\text { Subordinate }\end{array}$ & $\begin{array}{l}2 \\
7\end{array}$ & $\begin{array}{r}22 \\
7\end{array}$ & $\begin{array}{l}0 \\
9\end{array}$ & $\begin{array}{r}23 \\
0\end{array}$ & $\begin{array}{r}0 \\
14\end{array}$ & $\begin{array}{l}1 \\
0\end{array}$ & $\begin{array}{l}15 \\
18\end{array}$ & 7 & 1 & 25 & 1 \\
\hline Total & $\begin{array}{l}\text { Dominant } \\
\text { Subordinate }\end{array}$ & $\begin{array}{l}45 \\
57\end{array}$ & $\begin{array}{l}185 \\
102\end{array}$ & $\begin{array}{r}3 \\
57\end{array}$ & $\begin{array}{r}172 \\
23\end{array}$ & $\begin{array}{r}68 \\
218\end{array}$ & $\begin{array}{r}110 \\
57\end{array}$ & $\begin{array}{l}238 \\
249\end{array}$ & 73 & 28 & 293 & 150 \\
\hline
\end{tabular}

other's nose or face and hanging on tenaciously until physically separated by the E. Sustained biting was especially characteristic of that individual who later proved to be the alpha male. After a few trials, it was apparent that once such a grip was secured the bitten animal had little chance of freeing itself. At this point a decision was made to terminate all trials in which unilateral biting was sustained for more than $2.3 \mathrm{sec}$ and to judge the bitten pair member as loser. Of the 28 remaining trials on Day 1, 13 were terminated for this reason.

In contrast to these initial encounters, sustained biting rarely occurred in succeeding days of testing. Only three encounters on Day 2 had to be terminated for this reason and this frequency was never exceeded in any of the following test sessions. Thus, although biting continued to be frequent on Days 2-4, it was less severe, and victims typically escaped with relatively minor injury.

The frequency with which various behavioral components were observed is listed in Table 2. Although some of these behaviors occurred more than once within the same encounter, this tabulation depicts only whether or not a given component was present in each of the 36 daily pairings. The dominant-subordinate classification in Table 2 is based on the outcome of each separate encounter, with the exception that animals involved in a "tie" ( $30 \mathrm{sec}$ of shock with no criterion submissive response) were assigned a status commensurate with the overall win/loss ratio between that pair. These unresolved trials represented only $5 \%$ (18 of 360 ) of the total encounters.

Some of the behavioral categories listed in Table 2 are also illustrated in Figs. 1-6 and are referred to, when appropriate, in the following discussion. All drawings were traced from photographs developed from the motion picture record.

\section{Avoiding Shock}

As noted earlier, this category refers only to those behaviors directly elicited by shock itself. Most of the instances reported in Table 2 occurred at shock onset and consisted of a stereotypic, circular, hopping movement. Animals engaged in this activity frequently bit the grid rods. There were also a few instances of apparent attempts to jump out of the apparatus at the onset of shock which were included in this category. While it seems likely that Ss were attempting to avoid or minimize shock by rearing up on their hind legs, this was virtually always accompanied by visual and postural orientation toward the other pair member and, thus. was not considered to be a "pure" case of shock avoidance.

As shown in Table 2, there was no systematic tendency for shock avoidance behaviors to either increase or decrease over days. Nor was there any apparent relationship between this response and the social status of pair members. Indeed. perhaps the most consistent finding was one of relatively stable individual differences. Both the highest and lowest ranking Ss. for example, were "avoiders." while certain other Ss never emitted this type of response.

\section{Initial Attack Patterns}

Generally. both animals would establish visual and 
Note-Figures 1-4 show a typical sequence of events in the latter days of testing. The encounter depicted here is between two male Ss on Day 9. Time to criterion submission was $10.2 \mathrm{sec}$. Figures 5 and 6 are isolated incidents from other encounters.

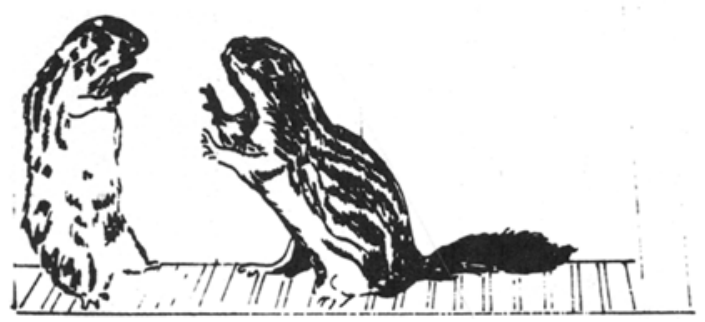

Fig. 1. Sparring posture of ground squirrels. The dominant squirrel (on the right) made a few steps forward and both animals have just assumed the upright posture prior to active sparring.

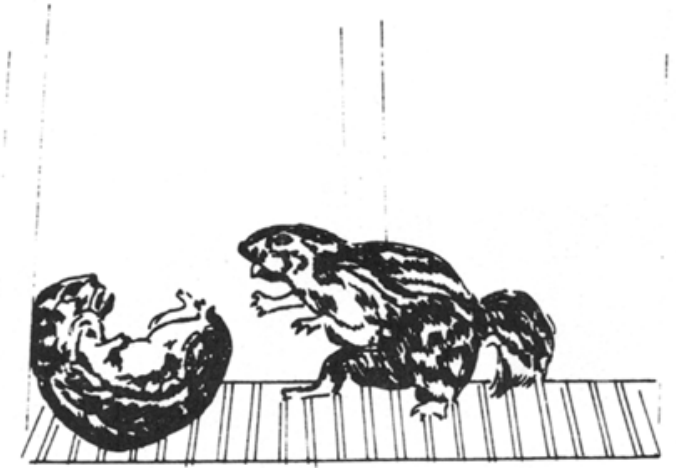

Fig. 2. Following active sparring, the submissive ground squirrel (on the left) has fallen on its back, while the dominant has assumed an upright threat display.

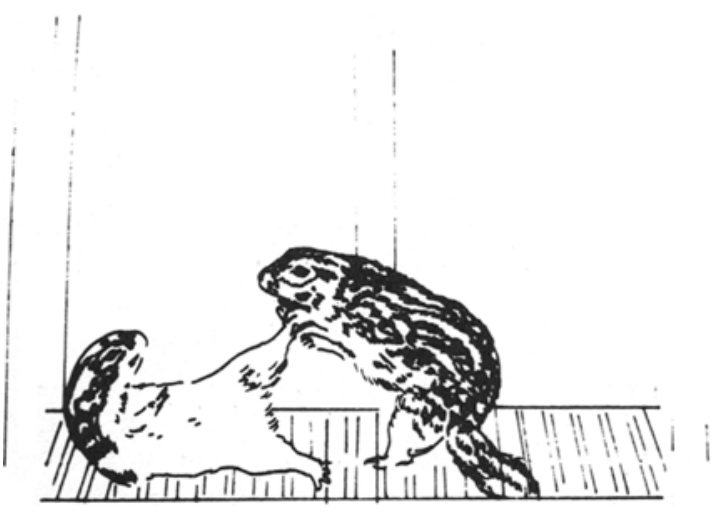

Fig. 3. The dominant squirrel has moved a step or two closer. The submissive is still down but maintains eye contact and is using an extended hindleg to hold off the dominant.

position of the tail, relative head elevation, or vocalization. The higher an animal's rank, the more frequently it assumed threat postures (Rho $=+0.71$, $\mathrm{p}<.05$ ).

Mutual threat was rare throughout testing (Table 2), postural orientation toward each other as the door separating their respective compartments was raised. Usually this did not require much adjustment, as Ss were always positioned facing the door and tended to remain relatively immobile until shock onset.

In the early test sessions, attack typically involved a lunging thrust forward, resulting in physical contact with subsequent biting and wrestling. Initial approach movements in the latter sessions were slower and typically resulted in one or both animals displaying a threat posture just short of physical contact and/or in both assuming an upright sparring posture.

Table 2 shows a tendency for the animal initiating attack to win that encounter. Further, $60 \%$ (62 of 102) of those instances where a squirrel initiated approach but lost the encounter involved pair members whose final status difference was one rank.

Mutual attack (i.e., simultaneous approach movements) remained at a relatively low but consistent frequency throughout testing (Table 2). These followed the same general pattern described above, with early sessions characterized by both animals leaping toward each other and latter sessions characterized by a more cautious approach and a tendency to resort to posturing with minimal physical contact.

\section{Avoidance of Attack}

This category refers to those instances where one animal terminated eye contact and moved as if to escape from an approaching pair member. While apparently a submissive act (i.e., flight), this behavior was dysfunctional in the small space of the experimental chamber and was relatively rare after the initial day of testing (Table 2). Of the 60 trials in which attack avoidance was observed, $70 \%$ were attributed to the two lowest ranking Ss. Typical patterns of avoiding attack were either to leap out of the way and run about the chamber or to simply turn away and crouch facing into the nearest corner. In most encounters where an animal avoided attack, that individual later showed criterion submission. There were, however, a few cases of persistent attack avoidance that resulted in $30 \mathrm{sec}$ of shock and no criterion submissive response. This type of behavior accounts for 25\% (9 of 36) of the "ties" reported in Table 1.

\section{Threat Postures}

Table 2 shows a systematic increase in threat displays during the course of the experiment. The threat stance varied from an upright crouching position (Fig. 2) to one on three or four legs (Fig. 6). Common components of this display were an extended head with mouth open and eyes fixated while in rigid visual and postural orientation toward the other pair member. Review of the written and film records revealed that threat postures were not clearly associated with piloerection, 
referred to here typically involved a sequence of events such as: threat, spar, one animal down, threat, downed animal showing criterion submissive response. Our operating rule for distinguishing threat displays from other forms of eliciting submission was the amount of physical contact required. Figure 6, for example, depicts an instance where threat was sufficient to elicit submission, while Figs. 1.4 illustrate an encounter where more physical contact was needed.

\section{Down on Side or Back}

All instances of lying temporarily immobile followed sparring or wrestling episodes. In the early days of testing, it usually occurred as a temporary respite in wrestling, with both animals in the downed position (Fig. 5). In later sessions, it was more likely to result from sparring activity, with only the submissive pair member being downed (Table 2). Immobility typically lasted for $2-3 \mathrm{sec}$, with slight movement or resumption of eye contact leading to further interaction. Thus, as testing proceeded, dominant animals were less likely to be downed, while submissive pair members were more likely to stay down, remain immobile, and emit a criterion submissive response.

\section{Biting}

Biting decreased over days (Table 2) as status relationships developed and stabilized. As noted earlier, biting on Day 1 was often sustained and injurious, with the most severe wounds being inflicted by the alpha male. Biting continued to be frequent, though less intense, on Days 2-4. The frequency of apparent attempts at biting during these early sessions, however, made it increasingly difficult to keep track of what were and were not fresh wounds. The frequencies listed in Table 2 are thus, at best, a rough approximation of actual biting and probably somewhat inflated. In any case, there was a rapid decrease in actual and/or attempted biting beginning at Day 4 and decreasing systematically thereafter.

Overall, females were wounded more frequently and severely than males. These severe wounds were in the facial area and involved deep penetration of the nose and palate. In contrast, neither the alpha nor the lowest ranking male had any detectable wounds, while the other males had numerous but relatively minor surface wounds. Most biting activity, whether or not injurious, was confined to the head and facial areas.

\section{Vocalization}

Vocalization by one or both pair members was common throughout the study. Although two distinct calls were discriminated, only one of these was included in the vocalization category of Table 2. Not included is a low-pitched whimpering sound that appeared to be

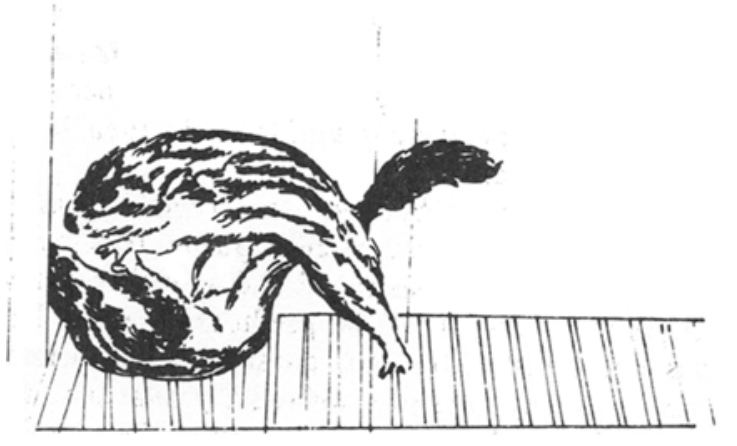

Fig. 4. The dominant squirrel continues to advance and is now hovering directly over the submiscive. The submissive squirrel, in turn, has averted its head backward, closed its eyes, and remained completely immobile in a full submissive display.

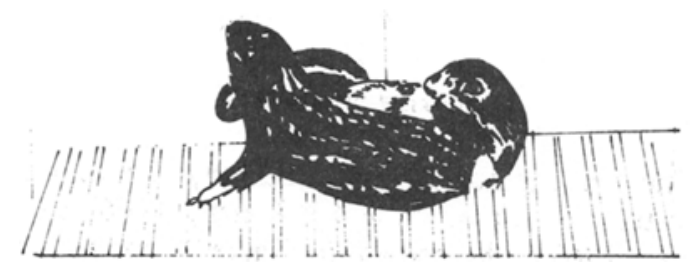

Fig. 5. Following a wrestling bout, both pair members remain temporarily immobile in downed positions.

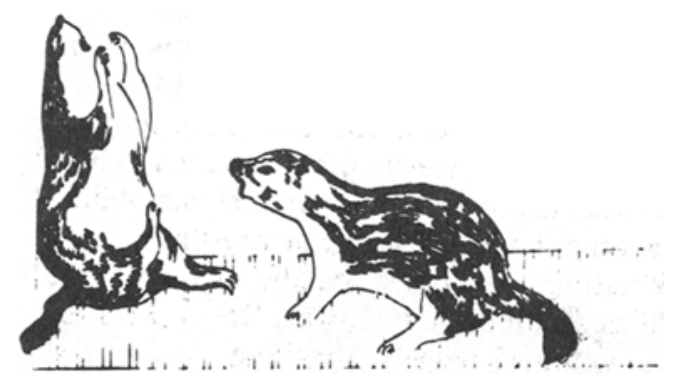

Fig. 6. A dominant ground squirrel (on the right) has assumed a threat posture which in this case was sufficient to elicit a full submissive response from the other squirrel.

although, for reasons presently unclear, it tended to occur most frequently in male-female interactions.

Threat postures did not always effect a criterion submissive response. although the tendency for this to happen increased over days. It should be made clear. however, that the threat categories in Table 2 refer only to the presence or absence of threat displays during the initial phase of an encounter. These. in fact. seldom led directly to criterion submission. The general partern 
uniquely associated with handling. It typically began when Ss were placed in the chamber and stopped when the door was raised to begin a trial. It also occurred frequently as animals were placed back in their home cages following a trial.

The vocalization tabulated in Table 2 was a high-pitched chirp delivered in short bursts. It occurred most often as the door was raised and animals oriented to each other during the $5-\mathrm{sec}$ preshock interval. This call was occasionally, but not consistently, associated with threat displays and was not reliably related to the status of pair members. Some Ss emitted the chirping call on almost every trial, while others did so rarely or never. It is worthy of note, however, that those Ss who chirped in the chamber also did so when approached in their home cage by any laboratory visitor. Possibly this is an alarm call given by highly "reactive" individuals, as in prairie dogs (King, 1955).

While individual differences in vocalization were quite stable, there was no apparent relationship between the two discriminated calls. That is, some Ss only "whimpered," others only "chirped," while others characteristically emitted either both or neither calls.

\section{Sparring and Wrestling}

The sparring posture was essentially the same as that reported for other rodents (Ulrich, 1966; Logan \& Boice, 1969). As shown in Table 2, sparring was a frequent and consistent activity, occurring in $81 \%$ (293 of 360 ) of all encounters. Sparring episodes were brief $(2-4 \mathrm{sec})$ and evolved into other activities when one or both animals was knocked down.

The typical pattern in early sessions was for one pair member to be knocked backward out of the upright stance and for the other to fall forward and quickly pounce upon him. The animals would then clasp their legs about each other and bite while rolling around on the floor. These wrestling bouts were also brief $(2-3 \mathrm{sec})$ and often led to temporary mutual immobility, followed by another bout of sparring or wrestling.

Wrestling diminished rapidly as dominance relations stabilized (Table 2). Following Day 5, wrestling episodes were confined largely to those encounters involving middle-ranking animals of similar status.

Later in testing the dominant pair member usually remained standing following a sparring episode and would assume a threat posture rather than jump on the fallen animal. If the downed $S$ did not avert its head or close its eyes, the dominant squirrel advanced closer, moving so as to hover over the other face to face (Figs. 1-4). This sufficed to elicit criterion submission in the fallen squirrel. Both pair members would remain rigid in these positions until separated by the $E$. On the latter few trials of a testing session, animals were often left in these dominant-subordinate positions as a test of persistence. The Es were always the first to disrupt the postures in waits up to $20 \mathrm{~min}$.

\section{DISCUSSION}

Testing paired ground squirrels in a shock-induced aggression paradigm produced a stable pattern of dominant-subordinate relations. Aggressive encounters decreased in both intensity and duration over days, with suppression of biting and wrestling accompanied by an increase in the frequency and effectiveness with which postural displays were used to resolve dominance. The problem of injury, while present in the initial stage of testing, was not prohibitive. Except for one S, who lost teeth and was removed from the study, injuries had no apparent effect on the recipient's ability or propensity to interact in subsequent encounters.

Results of this study clearly show that shocked ground squirrels have no single stereotyped fighting response. Although Ss frequently assumed the upright sparring posture, this was but part of an ongoing sequence of activities and increasingly led directly to dominant-subordinate posturing. The present Ss emitted a varied repertoire that included both offensive and defensive activities and modified their responses on the basis of prior experience with each other. Thus, by the latter days of testing, Ss were showing a differential responsiveness that was attributable to the established social stimulus value of opponents. A given squirrel, for instance, would rapidly display a submissive posture when matched with a more dominant individual. If, a few moments later, the same animal was paired with a social subordinate, it would assume an offensive attitude and elicit a submissive response from it's opponent. This is consistent with growing evidence that ground squirrels show individual recognition which presumably functions to stabilize status relations and to reduce the severity of conflict (Sheppard \& Yoshida, 1971).

Comparison of the present findings with field reports of the fighting behavior of sciurid rodents must remain highly tentative, as neither source of data is very conclusive at present. Obvious limitations of this study include the fact that there appeared to be a number of stable and potentially important individual differences in the small sample employed. The available field literature, in turn, includes various types of ground squirrels whose sociobiological variations are largely unknown. The following discussion is, thus, merely suggestive of various factors in need of further investigation under both laboratory and field conditions.

\section{Dominance}

It seems reasonable to assume that the general function of dominance under these laboratory conditions is comparable to what takes place in nature, i.e., to reduce the severity of conflict and prevent fatalities. The highly controlled setting, however, may have produced a more stable hierarchy than would occur in nature, where alternative factors such as territory, food competition, or mating privilege are operative. 
Wirtz (1967) reports that free-living mantled ground squirrels have a social hierarchy in which dominance is a group arrangement rather than a straight-line relationship. Thus, while overall win/loss ratios remain fairly stable, the result of a given encounter between two individuals cannot be predicted with any certainty. There is also the problem of assuming that different laboratory measures of dominance will correlate with each other (Baenninger, 1970), al though correspondence may be higher in wild rodents than in domestic rats (Boice, 1972). The present method of determining dominance does have the apparent advantage of enhancing social posturing and may have more merit for the study of intraspecific processes than other laboratory techniques.

The personal qualities that influence an animal's social standing are still unclear, although body weight appears to be of little consequence under laboratory or field conditions (Wirtz, 1967). In general, males appear to be more aggressive and to dominate females. This may vary with seasonal and/or hormonal factors, as Balph and Stokes (1963) note that female Unita ground squirrels become dominant following the breeding season.

\section{Escape vs Submissive Posturing}

The most common form of agonistic encounter in free-living ground squirrels involves a lower ranking animal escaping and being chased by the dominant. While subordinates may threaten and then fell, fight and then flee, or merely run from the approach of a dominant. the type of submissive display obtained in the present study is apparently not a characteristic response in natural settings.

Balph and Stokes (1963) report that, al though subordinate Unita ground squirrels sometimes adopt a slouched position and remain motionless until a dominant gets close, they were never observed becoming passive or adopting a supine position when at tacked. The high incidence of submissive posturing in the present study is, thus, obviously an adaptation to space restriction and not indicative of its prevalence in the wild. It should be noted, however, that "infrequent" is not synonymous with "unnatural." The fact that submissive displays functioned to reduce the intensity of attack by aggressors implies that such postures are socially meaningful and can serve to accomplish the same result as flight. It is our contention that prevention of flight may, in fact, reveal certain aspects of agonistic behavior that exist in nature but are relatively difficult to observe.

\section{Sparring}

Balph and Stokes (1963) are adamant in noting that free-living ground squirrels never stand upright and spar during an aggressive encounter. While there is little question that this is a somewhat unnatural activity for ground squirrels, its effects appear to be considerably less ambivalent for this species than for domestic rats. In the present study, sparring increasingly led to predictable and unambiguous dominant-subordinate posturing and seemed to function as a means of resolving conflict with minimal physical contact. It might be possible to reduce sparring by increasing the size of the experimental chamber.

\section{Threat}

The general usage and incidence of threat postures was consistent with what would be expected under free-living conditions. That is, threat was more likely to be displayed by the higher ranking animal and became more frequent as status relations were established. There are some inconsistencies between the threat components described by Balph and Stokes (1963) for the Unita ground squirrel and those reported here. They report that a threatening animal may growl or clatter its teeth and that the tail is held to one side with tail hairs erect. None of these components were found to be reliably associated with threat in the present study. Similarly, Balph and Stokes do not report the upright threat with back arched and head held low (Fig. 2) that was frequently emitted by our Ss. Wolfe (1966), however. does describe a similar threat posture for chipmunks. It was our general impression that some of the components commonly associated with threat vary considerably with the situation and individual. This would seem to be an area in which further laboratory study could prove fruitful.

Finally, it seems apparent that shocked ground squirrels exhibit a range and vigor of agonistic behavior that is quite distinct from the so-called "reflexive" fighting response commonly reported for laboratory rats (Ulrich \& Azrin, 1962). One implication of these findings is to suggest major behavioral differences across species in the sense that shock-induced forms of aggression may be less reflexive and nonsocial for some species than for others. The present data are. of course. not conclusive in this respect, as it is not yet clear to what extent procedural modification of the footshock contingency was responsible for enhancing the salience of intraspecific cues. There is, however, sufficient justification for concluding that elicited aggression techniques can be usefully adapted for comparative study and that this method may have merit for investigating the functions and effects of various agonistic behaviors, including postural displays.

\section{REFERENCES}

Balph. D. F.. \& Stokes, A. W. On the ethology of a population of inita ground squirrels. American Midland Naturalist. 1963. 69. 106-126.

Baenninger. L. P. Social dominance orders in the rat: "Spontancous" food and water competition. Journal of Comparative \& Physiological Psychology. 1970. 71, 202-209. 
Baenninger. R.. \& Grossman. J. C. Some effects of punishment on pain-elicited aggression. Journal of the Experimental Analysis of Behavior. 1969. 12, 1017-1022.

Barnett. S. A. An analysis of social behavior in wild rats. Proceedings of the Zoological Society of London, 1958, 130. 107-152.

Boice, $\mathbf{R}$. Some behavioral tests of domestication in Norway rats. Behavior, 1972, 42, 198-231.

Bolles, R. C. Species-specific defense reactions and avoidance learning. Psychological Review. 1970, 77, 32-48.

Clark, C. H.. \& Schein, M. Activities associated with conflict behavior in mice. Animal Behavior, 1966, 14, 44-49.

Collias, N. E. Aggressive behavior among vertebrate animals. Psychological Zoology, 1950, 16. 83-123.

Denniston, R. H. Escape and avoidance learning as a function of emotionality level in the Wyoming ground squirrel, Citellus richardsoni elegans. Animal Behavior, 1959, 7, 241-243.

Ginsburg. B., \& Allee, W. C. Some effects of conditioning on social dominance and subordination in inbred strains of mice. Physiological Zoology. 1942, 15, 485-506.

Hutchinson. R. R., Ulrich. R. E., \& Azrin, N. H. Effects of age and related factors on the pain-aggression reaction. Journal of Comparative \& Physiological Psychology, 1965, 59, 365-369.

King, J. A. Social behavior, social organization, and population dynamics in a black-tailed prairie dog town in the Black Hills of South Dakota. Contributions of the Laboratory of Vertebrate Biology, 1955, 67, 1-123.

King, J. A. Recent findings in the experimental analysis of aggression. American Zoologist, 1966, 6, 628.

Logan, F. A., \& Boice, R. Aggressive behaviors of paired rodents in an avoidance context. Behavior. 1969, 34, 161-183.
Reynierse, J. H. Submissive postures during shock-elicited aggression. Animal Behavior, 1971, 19, 102-107.

Rongstad, O. J. A life history of thirteen-lined ground squirrels in southern Wisconsin. Journal of Mammalogy, 1965, 46. 76-87.

Scott, J. P. Agonistic behavior of mice and rats: A review. American Zoologist, 1966, 6, 683-701.

Seligman, M. F. P., \& Maier, S. F. Failure to escape traumatic shock. Journal of Experimental Psychology, 1967, 74, 1-9.

Sheppard, D. H., \& Yoshida, S. M. Social behavior in captive Richardson's ground squirrels. Journal of Mammalogy, 1971, 52, 793-799.

Ulrich, R. Pain as a cause of aggression. American Zoologist, $1966,6,643-662$.

Ulrich, R., \& Azrin, N. H. Reflexive fighting in response to aversive stimulation. Journal of the Experimental Analysis of Behavior, 1962, 5, 511-520.

Uyeno, E. T., \& White, M. Social isolation and dominance behavior. Journal of Comparative \& Physiological Psychology, $1967,63,157-159$.

Wirtz, J. H. Social dominance in the golden-mantled ground squirrel, Citellus lateralis chrysodeinus (Merriam). Zeitschrift fur Tierpsychologie, 1967, 24, 342-350.

Wolfe, J. L. Agonistic behavior and dominance relationships of the eastern chipmunk, Tamias striatus. American Midland Naturalist, 1966, 76, 190-200.

(Received for publication September 12, 1972; revision received July 2, 1973.) 